University of Nebraska - Lincoln

DigitalCommons@University of Nebraska - Lincoln

Faculty Publications: Department of Teaching, Department of Teaching, Learning and Teacher Learning and Teacher Education

Education

$1-1-2005$

\title{
An Action Research Project on Preparing Teachers to Meet the Needs of Underserved Student Populations
}

Gayle A. Buck

University of Nebraska-Lincoln, gabuck@indiana.edu

Jeanene G. Cordes

University of Nebraska-Lincoln

Follow this and additional works at: https://digitalcommons.unl.edu/teachlearnfacpub

Part of the Teacher Education and Professional Development Commons

Buck, Gayle A. and Cordes, Jeanene G., "An Action Research Project on Preparing Teachers to Meet the Needs of Underserved Student Populations" (2005). Faculty Publications: Department of Teaching, Learning and Teacher Education. 11.

https://digitalcommons.unl.edu/teachlearnfacpub/11

This Article is brought to you for free and open access by the Department of Teaching, Learning and Teacher Education at DigitalCommons@University of Nebraska - Lincoln. It has been accepted for inclusion in Faculty Publications: Department of Teaching, Learning and Teacher Education by an authorized administrator of DigitalCommons@University of Nebraska - Lincoln. 


\title{
An Action Research Project on Preparing Teachers to Meet the Needs of Underserved Student Populations
}

\author{
Gayle A. Buck \\ University of Nebraska-Lincoln, Lincoln, NE, U.S.A.

\section{Jeanene G. Cordes} \\ University of Nebraska-Lincoln, Lincoln, NE, U.S.A.
}

\begin{abstract}
The focus of this action research study was on the initial stage in reforming our teacher preparation programs. We designed, conducted, evaluated, and revised the components of our teacher preparation prog rams that were aimed at providing preservice teachers with the confidence and knowledge needed to meet the needs of youth populations underserved in science education. The conceptual framework of this study predicted that providing preservice teachers with experiences in teaching science to at-risk youth in a nonformal educational setting and that exploring these experiences in a seminar setting will increase the teachers' confidence and knowledge in regard to teaching science to children from underserved populations. The community-based experience allowed for an experience in which 20 preservice teachers taught in a situation in which at-risk youth were the majority, thus spotlighting their needs in a manner traditionally not experienced by these prospective teachers. A two-phase methodological design (J. Creswell, 1994) was utilized to answer the questions: (a) Did the plan lead to the desired outcomes? and (b) What strategies fostered or hindered progress toward the desired outcomes? The findings of this study were utilized to develop our next action step in preparing teachers to foster science literacy for All Americans.
\end{abstract}

\section{Introduction}

The national goal for science education is science literacy for all Americans (National Research Council, 1996). This emphasis has emerged from the understanding that all students, regardless of their starting points in life, should be provided with the scientific skills and knowledge necessary to engage in the various disciplines deeply and intellectually (Cohen \& Bames, 1993; Meier, 1995). Many proponents of this national agenda stress the importance of reform initiatives that make structures and practices accessible so that each individual can succeed (Anderson, 1991; Delpit, 1988).

During this period of science education reform, the student population ratios in U.S. classrooms have been undergoing changes. Over the last 10 years, the population of English language learners has increased by 1 million students (Clair 
\& Adger, 1999). Thirty-nine percent of all teachers now have English-language learners in their classrooms (Sleeter, 2001). The number of students (K-12) from minority populations is rapidly increasing, with projections of continued growth to $46 \%$ by 2020 (Banks, 1991). There has also been an increase in the number of children with learning disabilities. Currently, 5-10 million children have learning disabilities (Hallahan \& Kauffman, 2000). In part, this is contributed to an increase of the number of children who live in poverty. This group has increased from 1519\% since the 1970s (Hallahan \& Kauffman, 2000). Unfortunately, these student populations represent children who have historically been underserved by science education (National Research Council, 1996).

In light of science education reforms and the increasing percentage of youth from populations traditionally underserved by science education, calls for reform in science teacher preparation emphasize the importance of helping teachers develop the confidence and knowledge needed for these diverse classrooms.

\section{Purpose}

As teacher educators we are committed to providing our students with authentic experiences in teaching science. For more than 40 years, our teacher education programs have been able to provide our students with experiences in classrooms that were successfully meeting the needs of their student population. Now we were depending on our field placement sites to also provide our preservice teachers with experiences in successfully meeting the needs of students from underserved populations. However, with the rapidly changing face of the classroom population, the field sites were depending on our preservice teachers and subsequent graduates to bring with them the contemporary knowledge and skills needed to help them create environments that would meet the needs of underserved science learners. We found ourselves looking elsewhere for a needed field placement that would provide our students with experiences in successfully meeting the needs of underserved populations of students. Our search led to discussions with local, nonprofit organizations within the surrounding area. These agencies were working with children from lowincome homes, exiting juvenile justice centers, entering emergency shelters due to domestic violence, or waiting placement in foster services. These youth represented many diverse ethnic, linguistic, and learning-disabled populations. They attended public schools in the area and were the ones most affected by the fact that many teachers were not prepared to meet diverse needs in the mainstream classroom. These discussions led to ideas of how to reform our teacher preparation programs to include an informal, diverse field experience.

The focus of this action research project was on preparing elementary and middle-level science teachers to meet the needs of children from underserved populations. We defined underserved as those students "who have traditionally not received encouragement and opportunity to pursue science-women and girls, students of color, students with disabilities, and students with limited English proficiency ... special students and differing sources of motivation" (National
Research Council, 1996, p. 221). This experience was based on the philosophy that any efforts to change classroom practice are likely to fail unless there are substantial opportunities to explore teachers' knowledge, beliefs, attitudes, and experiences (Haney, Czemiak, \& Lumpe, 1996). The conceptual framework of our plan of action predicted that providing teachers with experiences in teaching science to diverse learners in a nonformal educational setting and exploring these experience in a seminar setting will increase the teachers' confidence and knowledge in regard to teaching science to children from diverse populations and backgrounds. The community-based practice allowed for an experience in which at-risk youth were in the majority, thus spotlighting their needs in a manner traditionally not experienced by our prospective teachers.

\section{Guiding Literature}

The plan we describe in this study was designed and adjusted with the support of an extensive amount of literature. The focus of the literature search was guided by the goals of our effort: Increase preservice teachers' (a) level of confidence in teaching science to underrepresented populations in education, (b) knowledge of pedagogical strategies that foster or impede success for underrepresented populations, and (c) preparedness to teach science to students from diverse backgrounds. The following is a review of those pieces that we found to be most influential in our efforts.

In order to educate prospective teachers to work with youth from underserved populations, they must review and study their own images and beliefs. This exploration is necessary because they function as filters for making sense of the knowledge and experiences they will encounter. These beliefs and images also function as barriers to change by limiting the ideas that teacher education students are able and willing to entertain (Feiman-Nemser, 2001). Prior attitudes and values play huge role in the way preservice teachers interact with diverse students. Teachers often leave education programs with misconceptions about the history and culture of groups other than their own that are incomplete, misleading, and chauvinistic. Without intervention, these entering beliefs will continue to shape their ideas and practices within the classroom (Banks, 1991; Bullock, 1997; Feiman-Nemser, 2001; Zeichner, 1993). One of the current practices suggested is that of having preservice teachers explore their own cultural identities by writing autobiographies (Banks, 1991; Feiman-Nemser, 2001; Zeichner, 1993). Kanpol (1998) labeled a simila practice as "confession." In this practice, the student does the same type of selfanalysis. As preservice teachers reexamine their own attitudes and values toward cultural groups other than their own, they will be better able to understand and relate to other cultural groups (Banks, 1991; Listen \& Zeichner, 1990; Zeichner, 1993 Zeichner et al., 1998). In our project, we had teachers explore their own beliefs about underserved student populations. This was a prerequisite experience that we believe the preservice teachers needed to influence their confidence, skills, and knowledge. Therefore, it became an early component of our action plan. Although this was not a research question, data was collected in this area to monitor that what we found to be a prerequisite experience was provided. 
Many researchers are noting that reflective practices in the student teaching practicum are beneficial for prospective teachers, as well as for students. Reflection serves to help the preservice teachers sort out their thinking about problematic situations that occur and helps them reflect about that situation (Listen \& Zeichner, 1990; Zeichner, 1990). A result from reflective preservice teaching is the development of research-based teachers who are willing to review and inquire into their own practices. In light of this, a distance-delivered reflection journal became part of our plan of action.

By using inquiry-oriented practices, such as teachers telling their stories, writing journals, doing action research, producing case studies, supervising each other, and so on, a great deal will be learned about preservice teachers' attitudes and opinions concerning diversity (Darling-Hammond, 1996; Feiman-Nemser, 2001; Zeichner, 1992). Zeichner further stated that these approaches have the potential to help preservice teachers realize the purposes of education in a democratic society. Using an inquiry approach for prospective teachers will allow them to become constructivist learners themselves (Zeichner \& Teitelbaum, 1982). This will stress the need to adapt instruction to students' skill levels, involving them actively in thinking about content and analyzing the situations as cited by Southerland and Gess-Newsome (1999). Using a practicum situation as a vehicle for this type of inquiry into teaching, as we did in this action plan, helped preservice teachers to become aware of the cognitive, social, and cultural dimensions of learning; the role of diversity in instruction; and how modifications of assessment and the curriculum contribute to learning (Southerland \& Gess-Newsome, 1999).

Another aspect of teacher preparation that institutes of higher education must incorporate into their programs is awareness of curriculum weaknesses that would create learning difficulties for a child of diversity. Equitable representation in curricular materials; equitable opportunities in the laboratory setting; and equitable evaluation of student performance are important information for prospective teachers to know (Bullock, 1997). Bullock also believes that preservice teachers are more apt to respond to novel instruction if it is presented in teacher training programs. In light of this, the students in this project worked with curricula from the surrounding public schools. They identified the strengths and weaknesses of the curricula. Based on their findings, they made appropriate adjustments.

Developing school and community relationships in teacher education programs assists preservice teachers in learning about diversity as it exists in the real world. A scaffolding or bridging between the cultures of school and home must be established (Zeichner, 1993). This will provide knowledge of the cultural elements that are relevant to the students as they enter the classroom of the practicum. There is a call for the broadening of the practicum to include more attention to the community domain. In this first action step, the preservice teacher worked with two programs that were part of a large community organization whose mission is to help children, youth, and their families grow to live safe, healthy, and productive lives.

\section{Modes of Inquiry}

\section{Research Orientation}

Our inquiry, how to better prepare science teachers to meet the needs of youth from underserved populations, came out of our practice. This question became the starting point for an action research project. Action research is a process of inquiry that produces practical knowledge that is useful to our everyday life (Reason \& Bradbury, 2002). The aim of this type of research is to improve our practice by using professional eyes to observe our own practice (Arhar, Holly, \& Kasten, 2001). There are several models of the process of action research (e.g., Arhar et al., 2001; Kemmis, 1988; Stringer, 1996; Wells, 1994). After reviewing these models, we concluded that it was the model described and illustrated by Kemmis (1988) that provided the process that would best guide our efforts. Kemmis's model includes reconnaissance, planning, first action step, monitoring, reflecting, rethinking, and evaluation. These are completed in a spiraling process in the following order (see Figure I):

Step 1: Reconnaissance: The first step in Kemmis's model is reconnaissance. This is a thorough look into what is happening now. In our study, we had completed the reconnaissance by reviewing our current teacher preparation programs and the current literature on teacher development.

Step 2: General Plan: The second step in Kemmis's model is the development of a general plan. In this step we developed a general plan to revise our program to

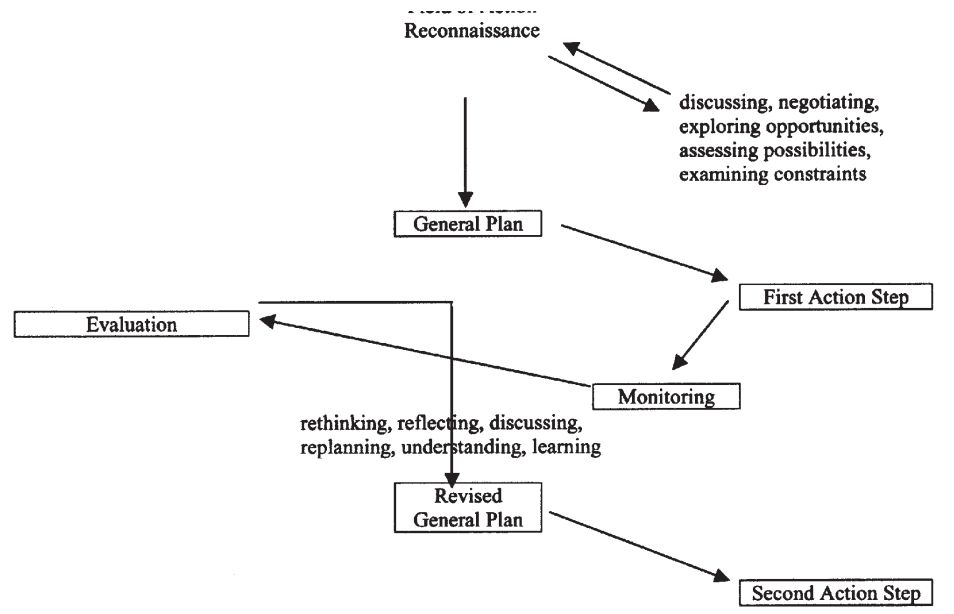

Figure 1. Lewin's Action Research Cycle. From Action Research in Retrospect and Prospect, p. 29, by Stephen Kemmis, 1990. 
include an informal field placement that located teachers in situations in which the majority of students were from underserved populations. This placement was to become part of the overall professional field placements, not replacing practice in the public school settings. The development of this component of our teacher preparation program became our first action step. Since this would require extensive effort and monitoring, we developed this component outside of the larger teacher preparation programs. This component was carefully monitored and evaluated. The findings from this action were utilized to revise this component in a manner that would allow it to become incorporated into our teacher preparation program.

Step 3: First Action Step: The third step in Kemmis's model is to take a first action step. Our first action step focused on the project. Preparing Teachers to Meet the Needs of Students From Underrepresented Populations in Science Education. This project was a collaborative effort between the College of Education and Human Sciences and nonprofit community organizations. This grant-funded experience supported a cohort of preservice teachers to take part in a seminar that focused on helping them develop the confidence and knowledge that would enable them to successfully educate children who are traditionally left out of science education. The students in this seminar completed $12 \mathrm{~h}$ of teaching in nonprofit organizations that work with at-risk youth, took part in five $2 \mathrm{~h}$ seminar meetings, and participated in a distance-delivered, reflection and discussion group.

The unifying structures of this course were programs at local community organizations. These programs sought to involve children from underrepresented populations in inquiry-based, science-learning activities. Course participants explored their beliefs about the populations represented in the programs, explored the societal and educational barriers that prevent diverse populations from succeeding in science education, learned skills that research has shown supports learning for such populations, and perfected their own teaching skills in a field teaching experience in which the minority populations were in the majority.

\section{Participants}

Since this program was in the trial stages and was the focus of a research project, student participation was voluntary. The students were recruited from the science methods courses that occurred in the semester prior to this program. For their participation, the participants received $2 \mathrm{~h}$ of graduate credit and $\$ 150$ worth of diversity materials at the completion of the seminar. To be eligible for the graduate credit, all applicants had to be within 1 year of graduation. All participants were working toward teaching certification in K-6 grades or 4-9 grades.

Overall, 22 preservice teachers responded to the advertisement for this field experience and seminar. Two of the students decided not to participate after the initial meeting, leaving 20 participants. All but one of the students completed the program $(N=19)$. This population included 17 females and 2 males. Ten of the participants were seeking certification in grades K-6 and nine were seeking certification in grades $4-9$.

\section{Outcomes Sought}

The first action step was designed and monitored in light of three major outcomes.

1. Increase preservice teachers' level of confidence in teaching science to underrepresented populations in education. Teachers are more likely to devote instruction time to science and use hands-on approaches if they have a positive attitude (Kagan, 1992; McDevitt, Heikkinen, Alcom, Ambrosio, \& Gardner, 1993).

2. Increase knowledge of pedagogical strategies that foster or impede success for underserved populations. In order to increase their effectiveness in teaching science to all children, teachers need to leam which methods research has shown will improve their instructional effectiveness in regard to the education of various underserved populations.

3. Increase teachers' preparedness to teach students from diverse backgrounds. Knowledge of the type of pedagogical strategies that research has shown to benefit diverse student populations is not enough. Teachers need to practice and refine their own skills in this area.

\section{Seminar Meetings}

There were five seminar meetings. The first session involved an overview of the course structure, a Blackboard (http://www.blackboard.com) "how-to" session, an overview of community organizations, an exploration of the students' images and beliefs of diverse students, and the selection of inquiry-based science activities to be completed with the youth at the first field experience.

The second through fourth seminar meetings were structured around a jigsaw cooperative learning activity. This jigsaw activity involved students working on different parts of an investigation and bringing them together (Sharon, 1994). This project helped the students become experts of the needs of various underserved populations. They then worked to use the expertise in the classroom to critique and revise science curriculum for increasingly heterogeneous classrooms.

This jigsaw activity began with the second seminar session, which involved putting the participants into groups of three or four. Each group became an expert on one underserved population in science education-including the teaching strategies that foster learning for this group. Each group was then provided with a packet of research-based information on their population and access to the World Wide Web. This group of three or four preservice teachers worked to redevelop the science curriculum in such a way that it was conducive for their specific population of at risk children. This first step of the jigsaw activity, an activity that was continued for the next three seminar sessions, took approximately one half of this first seminar. 
During the second half of this seminar session, the entire group came back together and reviewed the special needs of one of the populations represented in the youth the students would teach in the field experiences (learning disabled) and worked together to redevelop four inquiry-based, science activities that were conducive for this population of youth. These activities were conducted during the second field experience. This second part of the session was developed so that the participants would actually experience what they were asked to complete in the seminar-redevelop lessons for at-risk youth. This theme continued through the remainder of the sessions and experiences.

During the third seminar session, the first half of the session was devoted to the jigsaw activity. Each jigsaw group of expert participants joined one other group. These two groups then presented to each other what they learned about their one specific population and how they redeveloped their activities. The joined groups then became the experts on the needs of two at-risk populations in science education and worked together to redevelop the activity so that it was conducive to both populations of youth (increasing complexity). The second half of this session also involved investigating the needs of another at-risk population (attention-deficit hyperactivity disorder) that was also represented in the youth of students in the field experience activities. This knowledge was then immediately applied as the students worked to redevelop four activities for the next field visit.

During the fourth seminar, the jigsaw groups that were combined previously then joined another combined group. The participants presented what they learned about their populations and the activity they redeveloped. The jigsaw group that was made up of experts from the four different populations then worked together to redevelop the science activity so that it was conducive to all four populations. During this portion of the jigsaw activity, the students were presented with some suggested inclusive strategies that supported and contradicted each other. A class discussion was led that explored what a teacher can do when the needs of some children conflict with the needs of others. The second half of this fourth seminar session involved looking at conflicting needs of the different populations represented at the field experiences, discussing how to work through these conflicts, and applying this knowledge to the design of four activities for the next visit.

During the fifth seminar, the participants were asked to bring in a science unit that they had previously conducted. They worked together to make their science lessons more inclusive for all children. Following this we then explored what it means to make a public school classroom more inclusive. This session also included the completion of postproject, data-collection instruments and course evaluation.

By the end of the five seminar sessions, the students had become "experts" on the five different at-risk populations investigated in the jigsaw activity, in addition to the populations involved in the field experiences. They also worked to critique and revise science curricula with increasing complexity as they proceeded. With the support of the fieldwork activities, the students also practiced many of the inclusive strategies covered in the seminar. The final seminars were designed to focus less on applying the strategies to the field and more to applying the strategies to their own teaching situations.

\section{Field Experiences}

There were four field experiences. These occurred once a month for the entire seminar. The field experiences occurred at the community organizations. The facilities served either elementary- or middle-level-aged children. The children were in temporary residence at these facilities and, in most cases, were attending a local school. The children were placed in the facilities due to domestic violence, lack of current foster placement, or because they were in transition from a juvenile justice facility. Many different ethnic, linguistic, and learning-disabled populations were represented in all sponsored activities. Because of the temporary nature of the placements, the diversity structure of the learning groups changed throughout the program.

While at the facilities, the preservice teachers worked in groups of three to conduct 20-min, inquiry-based science activities (developed in the seminar sessions). The children were in groups of four to six and took part in four of the activities; the preservice teachers rotated from group to group. Employees of the youth organizations accompanied all groups of children. These employees were responsible for any behavior that can pose a threat to the other children or to the preservice teachers.

The first experience mainly focused on getting the youth involved and excited about learning science (emphasis on fun science). The activities that followed continued to be interesting for students, but the preservice teachers were responsible for teaching a coherent and accurate science concept to the youth. The activities were adapted to meet the unique needs of the population of youth represented in the experience (as discussed in the previous section).

The experiences took $2 \mathrm{~h}$, with time at the beginning and end to preview and review. The experiences were discussed in seminar and on-line discussions.

\section{On-Line Discussions}

All participants were expected to take part in several on-line discussions throughout the project. Thread topics developed and posted by one of the instructors focused these discussions. In total, participants were expected to post five responses and 10 replies to other participants. Sample thread topics included the preservice teachers' beliefs about diverse populations and teaching for diversity, what teaching for all students meant, and the application of inclusive strategies.

Step 4: Monitoring: The fourth step in Kemmis's model is monitoring. This step involved a thorough look into what happened in the first action step. Creswell (1994) has advanced three models of combined methodological design: two-phased design, dominant less dominant design, and mixed-methodology design. The two-phase design was best suited for the purposes of this researchanswering two distinct methodological questions that would guide us as we redesigned our teacher preparation program to better prepare teachers to meet the needs of diverse learners. A combination of approaches was utilized to answer the methodological questions: (a) Did the plan of action lead to the 
desired outcomes? and (b) What strategies fostered or hindered progress toward the desired outcomes? Both quantitative and qualitative data sought to answer the first question in a prove or disprove manner of whether this plan led to the desired outcomes. Qualitative data provided an interpretive view that sought to develop an understanding of the strategies utilized in the plan of action.

For reliability and validity purposes, multiple research approaches, multiple data sources, observers, peer debriefing, and an external auditor were utilized. However, this was a single-group quasi-experimental study in which certain controls for internal validity could not be addressed (i.e., level of sensitization of preservice teachers to desired outcomes).

\section{Data Collection}

All data collection instruments and processes were piloted prior to the research study. In light of findings from the pilot study, the processes and instruments described below were developed.

Questionnaire. All students $(N=19)$ completed a pre- and postquestionnaire (Spiegel, 2002) and course evaluations. The 60-item questionnaire was developed by an external consultant. This instrument was designed based on the intended outcomes of the project: increase preservice teachers' (a) level of confidence in teaching science to underrepresented populations in education, (b) knowledge of pedagogical strategies that foster or impede success for underrepresented populations, and (c) preparedness to teach science to students from diverse backgrounds. Alphas were calculated for the pilot instrument and used to guide final revisions. Sample questions included the following:

- Likert-type items:

1. I am unsure how to handle students with behavioral disorders in my science classroom.

2. In teaching science, I am confident that I can meet the needs of underrepresented populations.

3. Students who have behavioral disorders or learning disabilities respond best to text-based science lessons.

4. Sometimes a teacher needs to use different (lower) standards to grade students from different cultural backgrounds.

- How prepared are you to

1. teach science to groups that are heterogeneous in ability?

2. teach science to students with limited English proficiency?

3. encourage participation of minorities in science?
Written Reflections and Responses. As part of the program, the participants were asked to respond to reflection questions. These questions focused on the required readings and program experiences. These responses were posted to the seminar website. Sample response prompts included the following:

Based on this week's reading assignment, identify six strategies for motivating culturally diverse students. Will these strategies make your science lesson more appropriate for ALL students? (Response to others should focus on that last question.)

Field Notes. Each field experience was observed by one of the researchers. The researcher took notes on the activities, use of inclusive strategies, and interactions between preservice teachers and students.

Course Documents. The students were asked to develop activities for the program that incorporated their developing understandings of teaching diverse populations. A sample project included the final assignment:

The purpose of this last assignment is for you to take what we discussed and practiced in the seminar and apply it to YOUR practice. In light of this, I would like you to analyze and adjust a science lesson you previously developed and hope to teach in the future. This process should be accomplished in five steps. First, on the Web site, briefly describe your previous lesson (sum it up for us). Second, on the Web site, discuss the diverse student needs that the plan would meet (show that you understand the special needs and how you meet them). Third, on the Web site, discuss the diverse student needs the plan would not meet (ditto). Fourth, on the

Web site, discuss how the lesson could be adapted to better meet all needs.

Finally, bring and submit the final plan at our last seminar meeting.

Step 5: Evaluation: The fifth step in Kemmis's model is evaluation. This step involves seeking an understanding of the first action step through discussion and reflection. This evaluation was guided by the two methodological questions.

Phase I: Did the Plan of Action Lead to the Desired Outcomes?

Quantitative Analysis. Data from 20 preservice teacher questionnaires was collected, coded, and analyzed. An external, qualified consultant completed this. Because this study looked for a change from presemester to postsemester, only the students $(N=19)$ who completed both the presurvey and postsurvey were included in this summary of results. A t test was performed on the close-ended items. These items addressed several areas related to the preservice teachers' self-assessment on how confident they were to teach diverse students and their knowledge of the strategies that foster or impede success of underrepresented populations.

The male/female ratio was not sufficient to analyze by gender. However, the 10:9 ratio between students seeking a K-6 or $4-9$ certification was used to seek 


\section{Table 1}

Pre- and Posttreatment Mean Data on Level of Confidence in Meeting the Needs of Underrepresented Populations in Science Education

\begin{tabular}{llr}
\hline Overall & Pre $=3.4$ & Post $=4.3^{\mathrm{a}}$ \\
K-6 certification & Pre $=3.1$ & Post $=4.3$ \\
$4-9$ certification & Pre $=3.7$ & Post $=4.3$ \\
\hline
\end{tabular}

Note. All ratings are based on a 5-point scale with 1 being low.

${ }^{\mathrm{a}}$ Change $=0.9$, statistically significant $(p<0.001)$.

Table 2

Pre-and Posttreatment Mean Data on Knowledge of Pedagogical Strategies That Fosters or Impedes Success of Underrepresented Populations

\begin{tabular}{llc}
\hline Overall & Pre $=3.6$ & Post $=3.8^{\mathrm{a}}$ \\
K-6 certification & Pre $=3.6$ & Post $=3.8$ \\
$4-9$ certification & Pre $=3.7$ & Post $=3.8$ \\
\hline
\end{tabular}

Note. All ratings are based on a 5-point scale with 1 being low.

${ }^{a}$ Change $=0.2$, statistically significant $(p<0.05)$.

further patterns within the data set (see Table 1). At the beginning of the course, preservice teachers felt that they had some strategies and skills in meeting the instructional needs of students from diverse backgrounds, but they were not overly confident. The 4-9 certification preservice teachers were more confident in their skill level than the elementary teachers at the beginning of the semester. By the end of the semester, preservice teachers were significantly more likely to assess their own skill level positively and to agree with statements indicating a higher level of self-confidence in utilizing those skills (see Table 2). At the beginning of the semester, the majority of preservice teachers were somewhat aware of pedagogical strategies that foster or impede the success of students from underserved populations. There was a slight change in this scale by the end of the semester, indicating greater awareness (see Table 3). At the beginning of the seminar, most preservice teachers felt somewhat to fairly well prepared to do the things listed on the questionnaire. The middle-level preservice teachers felt much more prepared at the beginning of the seminar than the elementary preservice teachers. By the end of the semester, most preservice teachers (all certification levels) felt fairly well prepared and some felt very well prepared to teach students from diverse backgrounds. This overall change was statistically significant.

Qualitative Analysis. Qualitative analysis provided us with a technical understanding of the project. In brief, did the project increase the preservice teachers' confidence and knowledge in regard to teaching science to diverse student populations (yes or no)? The following review of the qualitative analysis illustrates an
Table 3

Pre- and Posttreatment Mean Data on Preparedness to Teach Students From Diverse Backgrounds (Self-Assessment)

\begin{tabular}{llr}
\hline Overall & Pre $=2.6$ & Post $=3.4^{\mathrm{a}}$ \\
K-6 certification & Pre $=2.2$ & Post $=3.5$ \\
$4-9$ certification & Pre $=3.0$ & Post $=3.4$ \\
\hline
\end{tabular}

Note. All ratings are based on a 4-point scale with 1 being low.

${ }^{a}$ Change $=0.8$, statistically significant $(p<0.001)$.

interpretive understanding of the types of knowledge the preservice teachers were gaining.

Open-Ended Questionnaire. The student responses to the open-ended items on the questionnaire were analyzed with respect to the extent to which they confirmed achievement of intended seminar outcomes. The open-ended items intended to address theses issues were the following:

1. What are your strengths and weaknesses with respect to helping students from underrepresented populations achieve?

2. What strategies do you plan to implement to promote the achievement of these underrepresented populations? (Please use specific examples, not generalities.)

When asked about their own strengths and weaknesses in working with students from underrepresented populations, the preservice teachers had diverse responses, only some of which were relevant to the identified goals (determining level of confidence). In the postsemester survey, about one third of the preservice teachers indicated that they had some awareness or some skills in meeting the needs of diverse learners. Responses included:

Strengths

- understanding how to include all learners

- planning a variety of lessons to reach different types of learners

- creative in lesson planning empathetic, break things down

- I know how, I can adjust lesson plans to meet needs, I am educated in various areas where students have specific needs.

These kinds of responses were not included in the pretest responses, so these were things that students felt they had gained during the semester. However, anothe one third of preservice teachers cited some specific weaknesses in these same areas. Responses included:

Weaknesses

- lack some skills in working with specific diverse groups

- I don't always know how to assist [those who are not achieving] 
- understanding how to accommodate all needs

- I don't know many contributions of minority groups

These specific weaknesses show an awareness that they recognize their own deficiencies, and they can be rather specific about what they need to leam, which indicates growth and change from the presemester surveys that were more vague in listing weaknesses.

When asked to cite some specific strategies that they planned to use in their own classrooms, a similar pattern emerged. While many of the preservice teachers had relevant and specific ideas to use at the start of the semester, almost half of the preservice teachers' responses at the end of the semester were more specific and detailed than their presemester surveys. The majority of those showing change were K-6 certification majors:

- Hands-on, inquiry-based with all students

- Find role model to which all students can connect

- Use small groups

- Break activities into smaller/simpler pieces

- Include role-model scientists from different backgrounds

- Make resources available

- Show and tell about great women scientists, scientists from other cultures, along with white male scientists

- Encourage all students to excel in science.

In particular, those who were more specific included such strategies as breaking down activities to make them manageable, including more diverse role models, using appropriate materials and resources, and incorporating more inquiry-based methods.

Conclusion for Evaluation of Phase I: Did the Plan of Action Lead to the Desired Outcomes. In conclusion, the 19 students enrolled in this course appeared to have gained some skills and confidence in working with students of underrepresented populations. They felt better prepared to teach science to these students, and their knowledge of appropriate pedagogical strategies increased over the course of the semester. While the elementary teachers appeared to make greater gains than the middle-level teachers, this appeared to be attributed mostly to the middle-level teachers' higher skill levels at the beginning of the semester. By the end of the project, both the elementary and middle-level teachers had relatively high and similar self-assessments of skill in teaching science to students from underrepresented populations.

Phase II: What Strategies Fostered or Hindered Progress Toward the Desired Outcomes?

Seminar documents, observations, seminar evaluations, and on-line responses were collected, coded, and analyzed. The coding was guided by systematic categories developed from the intended outcomes. Any datum that did not appear to fit these categories was evaluated to determine if a new category was warranted. The analysis was completed by the first researcher and the second researcher reviewed the analysis to verify that (a) the categories made sense in view of the data that were available and (b) the data had been appropriately arranged in the category system (Guba, 1978). Data from all participants were included in the summary of results. The male:female ratio between participants was not sufficient to analyze by gender In addition, a preliminary review of participant data by certification area revealed that analyzing by certification area was not warranted.

Seminar Meetings. Overall, the effectiveness of the seminar structure was monitored by collecting seminar documents, developing field notes of the seminar experiences, and copying seminar evaluations. Analysis of these data revealed that the structure of the seminar allowed the students to work to levels of greater complexity with ease and confidence. A review of field notes revealed that the student were continuously engaged in the process, made easy transitions to the next level of complexity, and made an easy conversion to applying the activities to the field experience. Analysis further revealed that many of the students noted that the use of cooperative learning fostered this type of progress. Several comments from the course evaluations referred to this cooperative work as the most valuable component of the seminar. Seminar students noted the following: "working in groups to find out the best strategies to teach diverse students," "working in cooperative groups to discuss various physical disabilities and leam how we could adjust activities to fit special needs," and "a chance to work in groups to help each other leam." They further demonstrated the value they placed on the interaction that this type of structure provided. Students noted the "awesome feedback during seminars" and that the "seminars were valuable to talk with classmates and the instructor."

These cooperative activities in the seminar all focused on authentic application. One student noted that the most valuable part was that "I applied it to my actual teaching experience." Final activities documented application level and preparedness. In this assignment, students used the skills and strategies they cooperatively learned and practiced in the seminar to individually develop an inclusive unit. The students took the units previously developed, identified the strengths and weaknesses in each unit applying to inclusive teachers, and revised the unit to better accommodate all learners. A review of those final assignments revealed that the students applied the knowledge and skills to appropriately revise science units. For example, after identifying the weaknesses on a previously developed unit on volcanoes, one participant revised the volcanoes to better meet the needs of students for whom English is a second language and for students who are visually impaired. This was accomplished in a manner that did not hinder the unit's identified strength-meeting the needs of the gifted child. Another participant revised a unit on graphing to better meet the needs of children with behavioral disorders and children with several types of learning disabilities.

The seminar fostered progress toward the intended outcomes. The most successful component seemed to be the transition and the cooperative nature of the 
activity. The structure of the seminar led to successful final products that were aimed at applying skills.

Field Experience. The effectiveness of the field experience was monitored by developing field notes of the experiences and seminar evaluations. Analysis of these data revealed that, over the course of the four experiences, the participants increased their degree of engagement, increased their ability to engage the students in the activities, and began to incorporate more inclusive strategies that had been discussed in the seminar. However, the level and degree of proficiency at utilizing inclusive strategies was low. Field notes showed that the apparent focus of the participants during the experiences was on completing a structured activity that incorporated very little, if any, inclusive strategies. In terms of completing that structured activity, early experience notes revealed that many of the preservice teachers were not able to complete their planned activities before they had to switch groups. As their focus was on activity completion, they seldom interacted with the children. As time went on, most preservice teachers completed their activities, appeared to be more at ease with the students, and several demonstrated inclusive strategies. Most groups allotted little or no time for comprehension checks. In later experiences, many of the preservice teachers commented that their lesson went very well, but they were unable to comment on student learning. Because of the fact that the time allowed for little or no informal evaluation data to be collected on the children, the success of the activities in terms of learning could not be noted nor reflected on by the preservice teachers.

Analysis further revealed that many of the participants valued this component of the seminar and felt better prepared to teach as a result. Several comments from the seminar evaluations demonstrated this. These field experience comments included: "the experience renewed my commitment to children" and "[most valuable of the experience was] working with kids." Many of the participants requested more time devoted to this strategy, requesting "more on-site experience, more experience at [site]-it was the most beneficial moment of the semester!" There were no negative reactions to the experiences; however, when asked for constructive suggestions, several students requested to "make [site] activities longer."

Over time, the participants became more comfortable at the sites and became freer in their interactions with the children. However, we question the value of these exchanges due to the fact that their use of inclusive strategies was low. This value cannot be further analyzed because of the lack of information on the children's learning. As preservice teachers made an attempt to adjust to the 20 min activity structure, the use of inclusive strategies began to appear. The progression of becoming more engaged to the initial identification of inclusive strategies appears to indicate that the students needed more time to build a relationship with the students and to become engaged in the activities.

On-Line Discussions. The project participants took part in several on-line discussions throughout the semester. The participants initially responded to threads initiated by the instructor and then responded to each others' responses. Sample topics included their beliefs about diverse populations and teaching for diversity, what teaching for all students meant, and the application of inclusive strategies. The overall structure of the on-line discussions was developed in a manner that led to increased (a) self-confidence by providing the students with a safe environment to perfect their ability to explain their beliefs and practices and (b) knowledge of inclusive practices by explaining, synthesizing, and judging the knowledge gained in the seminars and readings.

Overall, the effectiveness of the on-line discussions was monitored by the collection of written responses, rubric scorings, and seminar evaluations. Analysis of these data revealed that an equal number of students found the discussion to be useful as not useful. This was the strategy that produced the greatest discrepancy in student opinion. A number of students saw this strategy as a hinderance toward achieving the desired outcomes. These students commented thusly, "I learned more through the class time than the Blackboard responses." "Have weekly meetings instead of computer-interfaced instruction." and "Less computer stuff." An equal number of students saw this strategy as one that fostered achievement of course outcomes. These students made such comments as "The posting on Blackboard was good to see what other students were thinking. I enjoyed the opportunity to interact with students on the Web." "Blackboard discussions were very educational. The responses I made to others made me think." One participant stated that the on-line work was the most valuable component of the project.

Analysis also revealed a mixture of success in having students reflect and discuss course content. In some cases, the level of discussion did not lead to higher levels of knowledge. Student postings involved mostly content recall. Those postings included such phrases as "According to [author], there are six ways to motivate culturally diverse learners [goes on to recall content]" and "Portfolios are a great [goes on to describe what the reading noted on portfolios]." A lack of reflection on course content was also revealed in the analysis of many of the student responses to each other. Although asked to challenge ideas in a constructive manner, many students simply acknowledged other students' responses or restated students' answers. This was revealed with such statements as "I agree [goes on to restate the response]" and "I couldn't agree more [goes on to restate the response]."

A number of students did give insight into how this strategy could foster the achievement of program goals. Several student comments demonstrated increasing levels of knowledge construction. Such comments included "In your response you talk a lot about..." "But are you saying that...? " Are you denying...? " In addition, the reflections showed us which students were reflecting. Such postings included: "The book makes a point of culturally diverse scientists and women scientists that are isolated from the rest of the scientific community. I have a hard time agreeing with that in all aspects ..." "Your strategies were definitely mentioned in the readings. However, as I think about them for my own classroom, a couple of your examples cause me to wonder how possible they really are. For instance ..." This information proved extremely beneficial in guiding the seminars; however, the fact that such information was reflecting the experiences of only some of the participants proved to be a hindrance to reaching all students. Analysis also revealed that many 
students were reluctant to thoroughly explore their own beliefs or those of their classmates; however, several students were able to utilize this medium to explore and reflect and expressed a desire to have their classmates better challenge their understandings. [Problem] try to get students to analyze and critique each other's work. Many were reluctant to do this. Need more feedback.. .on the computer stuff."

Conclusion/or Evaluation of Phase II: What Are the Strategies That Fostered or Hindered Progress Toward the Desired Outcomes? In conclusion, the structure of the seminar for this first action step fostered progress toward the desired outcomes. Analysis did not indicate any necessary adjustments. However, adjustments are necessary in regard to the field experiences and on-line discussions. Although the students valued the field components and the interactions led to a greater comfort and sense of preparedness by the preservice teachers, the experiences hindered progress in three ways. First, the limited time with each group of children placed a perceived emphasis on activity completion, not student understanding, and prevented many of the preservice teachers from interacting with the children. Second, the lack of understanding of the children's learning did not allow for an accurate understanding of the experience. Third, the lack of emphasis on concepts to be learned and overemphasis on activities to be completed allowed for an incomplete understanding of inclusive teaching. The on-line discussion was the strategy most criticized by participants; however, the majority favored the interaction. The analysis revealed that the structure of this on-line component hindered progress in two ways. First, many students were allowed to respond to reflection questions by simply recalling facts from the reading; thus hindering progress toward greater understanding. Second, many students did not engage in critical and constructive responses to their peers.

Step 6: Revised General Plan: The sixth step in Kemmis's model is to develop a revised general plan. Based on our findings, we determined that this type of program does lead to the desired outcomes; however, there were several strategies that hindered progress toward these outcomes. We developed a revised general plan with these understandings.

\section{Seminar Meetings}

The structure of the seminar meetings will not change from that of the first action step. There will be five seminar meetings. These will occur on the university campus in the evenings. The first session will involve an overview of the course structure, a Blackboard (http://www.blackboard.com) how-to session, an overview of the community organizations, an exploration of the preservice students' images and beliefs of diverse students, and the selection of inquiry-based science activities to be completed with the youth on the first meeting.

The second through fourth seminar meetings will continue to be structured around a JIGSAW cooperative learning activity. The preservice teachers will work in groups as they develop an expertise that will prepare them to develop science activities for increasingly heterogeneous classrooms.
During the final seminar, the preservice teachers will bring in a science unit that they had previously conducted. They will work together to make these science units more inclusive for all students. Prior to the conclusion of this session, we will explore what it means to make a public school classroom more inclusive.

\section{Field Experiences}

The structure of the field experiences will be changed from that of the first action step. In light of the findings from the first program, three changes will be made. These are the following: (a) the preservice teachers will spend more time with each group of children at each experience, (b) the experiences will occur within a shorter time period, and (c) the preservice teachers will be held to curriculum objectives.

There will be four field experiences. These will occur once a week during the 9th-13th weeks of the 16 week seminar. The field experiences will occur at the community organizations. While at the facilities, the preservice teachers will work in groups of three to conduct 60-min, inquiry-based science activities (developed in the seminar). The children will be in groups of four to six and will remain in the same groups during the entire project.

The activities that are completed will continue to be interesting for students, but the teachers will be responsible for teaching coherent and accurate science concept that are taken from the National Science Education Standards (National Research Council, 1996). Each session will conclude with an authentic assessment activity that the preservice teachers will be asked to report and respond to on-line. In addition to these assessment results, the overall field experience will continue to be discussed in seminar and on-line discussions.

\section{On-Line Discussions}

The structure of the on-line discussions will be changed from that of the first action step. In light of the findings from the first program, three changes will be made. These include (a) the instructor of the seminar will take a greater role in facilitating critical discussion, especially in the early weeks of the seminar; (b) the rubric for the on-line discussion will be adjusted to include critical and constructive responses; and (c) a self-assessment component will be added to the on-line discussions.

All participants will be expected to take part in several on-line discussions throughout the project. Threads will be developed and posted by the instructor focused on leading these discussions. In total, participants will be expected to post one initial response to each of five different thread topics and two responses to other participants on each thread topic. On the first two on-line discussions, the instructor will respond to each initial response and at least one response for each student. With these responses, the instructor will point out areas that need further justification or clarification, pose critical and constructive questions, and suggest areas that could be further analyzed in order to develop guiding questions. The instructor's role will 
change to one of peer in the final three discussions, posting her own responses and responding to several other participants on each thread topic.

All initial responses and peer responses will be graded with a rubric. This rubric will be discussed at the initial seminar meeting, as well as posted on the Web site. This rubric has been adjusted to include critical and constructive responses. This rubric will be utilized by both instructor and students. Any major discrepancies will be discussed with students.

\section{Conclusion and Implications}

This inquiry came out of our practice. We sought to understand how to revise our teacher preparation program in a manner that would better provide the preservice teachers with the confidence and knowledge needed to meet the needs of youth populations underserved in science education. In light of the fact that many of the teachers in our field placements were themselves working to develop a better understanding of how to address the needs of diverse youth, we looked elsewhere for field placements that would provide the preservice teachers with experiences in successfully meeting the needs of underserved populations of students. Our search lead to the development of an informal, diverse field experience in local organizations that work with diverse youth populations. This informal field experience did lead to the desired outcomes; however, the progress toward these outcomes was hindered by an inadequate amount of time to get to know the students, extended periods of time between field experiences, a disconnection between the science activities and public school curriculums, and a lack of critical and constructive reflection by the preservice teachers on their own experiences, as well as on those of their peers. In light of these findings, we have revised our program and will implement these changes in the coming year. However, this process does not end with this implementation.

Action research is a cyclical process. Our newly developed program is but the second action plan. This second plan will also be carefully monitored to further inform our efforts in reforming our teacher preparation programs to better prepare teachers to foster scientific literacy for all students. This process must continue to focus on uncovering whether the program leads to the desired outcomes; however, we believe our focus must expand beyond the experiences of the preservice teachers. If we are to understand whether we are truly preparing these preservice teachers to meet the needs of youth populations underserved in science education, we must turn our focus to these children. This means we must take a longitudinal approach and follow our preservice teachers through their initial experiences as classroom teachers. These future inquiries must continue to inform our practice.

Although our experience has provided an initial model of a teacher development that prepares teachers to meet the needs of underserved student populations, one that can be adapted to other contexts, we believe the most powerful implication of the experience is that it supports a process of improving the practice of teacher preparation-action research. Practitioner research in higher education can provide "richer understandings of education and to the identification of.. /spaces for ethically defensible, politically strategic action" (Anderson, Herr, \& Nihien, 1994 , p. x). Preparing teachers for the changing student population is but one of the societal changes affecting our efforts. Our efforts must reflect the changing nature of education.

\section{References}

Anderson, C. (1991). Policy implications of research on science teaching and teachers' knowledge. In M. Kennedy (Ed.), Teaching academic subjects to diverse learners (pp. 5-30). New York: Teachers College.

Anderson, G., Herr, K., \& Nihien, A. (1994). Studying your own school. Thousand Oaks, CA: Corwin

Arhar, J., Holly, M., \& Kasten, W. (2001). Action research for teachers: Traveling the yellow brick road. Columbus, OH: Prentice-Hall.

Banks, J. (1991). Teaching multicultural literacy to teachers. Teaching Education, 4,135-144.

Bullock, L. (1997). Efficacy of a gender and ethnic equity in science education curriculum for preservice teachers. Journal of Research in Science Teaching, 34, 1019-1038

Clair, N., \& Adger, C. (1999). Professional development for teachers in culturally diverse schools. ERIC Digest: ED435185.

Cohen, D., \& Bames, C. (1993). Pedagogy and policy. In D. Cohen, M. McLaughlin, \& J. Talber (Eds.), Teaching for understanding: Challenges for policy and practice (pp. 207-239). San Francisco: Jossey-Bass.

Creswell, J. (1994). Research design: Qualitative \& quantitative approaches. Thousand Oaks, CA: Sage.

Darling-Hammond, L. (1996). The quiet revolution: Rethinking teacher development. Educational Leadership, 53(6), 4-10.

Delpit, L. (1988). The silenced dialogue: Power and pedagogy in educating other people's children. Harvard Educational Review, 58, 280-298.

Feiman-Nemser, S. (2001). From preparation to practice: Designing a continuum to strengthen and sustain teaching. Teachers College Record, 103, 1013-1055.

Guba, E. (1978), Toward a methodology ofnatuaralistic inquiry in educational evaluation. CSE Monograph Series in Evaluation No. 8. Los Angeles: University of California, Los Angeles, Center for the Study of Evaluation.

Hallahan, D., \& Kauffman, J. (2000). Exceptional learners. Boston: Allyn \& Bacon.

Haney, J., Czemiak, C., \& Lumpe, A. (1996). Teacher beliefs and intentions regarding the implementation of science education reform standards. Journal of Research in Science Teaching, 33, 971-993.

Kagan, D. (1992). Professional growth among preservice and beginning teachers. Review of Educational Research, 62, 129-169.

Kanpol, B. (1998). Confession as strength: A necessary condition for critical pedagogy. Educational Foundations, 12(2), 63-75. 
Kemmis, S. (1988). Action research in retrospect and prospect. Geelong, Victoria, Australia: Deakin University Press.

Liston, D., \& Zeichner, K. (1990). Teacher education and the social context of schooling: Issues for curriculum development. American Educational Research Journal, 27, 610-636.

McDevitt, T., Heikkinen, H., Alcom, J., Ambrosio, A., \& Gardner, A. (1993). Evaluation of the preparation of teachers in science and mathematics: Assessment of preservice teachers 9 attitudes and beliefs. Science Education, 77,593-610.

Meier, D. (1995). How our schools could be. Phi Delta Kappan, 76, 369-373.

National Research Council. (1996). National science education standards. Washington, DC: National Academy Press.

Reason, P., \& Bradbury, H. (2002). Handbook of action research: Participative inquiry and practice. Thousand Oaks, CA: Sage.

Sharon, S. (1994). Handbook of cooperative learning methods. Westport, CT: Greenwood.

Sleeter, C. (2001). Preparing teachers for culturally diverse schools: Research and the overwhelming presence of whiteness. Journal of Teacher Education, 52, 94-106.

Southerland, S., \& Gess-Newsome, J. (1999). Preservice teachers' view of inclusive science teaching as shaped by images of teaching, learning, and knowledge. Science Education, 83, 131-150.

Spiegel, A. (2002). Science education diversity: Preservice teacher opinions. Unpublished manuscript.

Stringer, E. (1996). Action research: A handbook for practitioners. Thousand Oaks, CA: Sage.

Wells, G. (1994). Changing schools from within: Creating communities of inquiry. Toronto, Ontario, Canada: OISE Press.

Zeichner, K. (1990). Changing directions in the practicum: Looking ahead to the 1990s. Journal of Education for Teaching, 16, 105-132.

Zeichner, K. (1992). Beyond inquiry-oriented teacher education: Rethinking the practicum (Rep. No. 1992-09-00). Saskatoon, Saskatchewan, Canada: Saskatchewan University.

Zeichner, K. (1993). Educating teachers for cultural diversity (NCRTL Special Rep. No. 1993-02-00). East Lansing: Michigan State University.

Zeichner, K., Grant, C., Gay, G., Gillette, M., Valli, L., \& Villegas, A. (1998). A research informed vision of good practice in multicultural teacher education: Design principles. Theory into Practice, 37, 163-171.

Zeichner, K., \& Teitelbaum, K. (1982). Personalized and inquiry-oriented teacher education: An analysis of two approaches to the development of curriculum for field-based experiences. Journal of Education for Teaching, 8, 95-117. 